$$
\begin{gathered}
\text { 인도네시아 아동들의 아침식사하기에 영향을 미치는 요인 분석 } \\
\text {-건강신념모델을 이용하여- } \\
\text { 강란이 }{ }^{1)} \text { - 이수진 }{ }^{1)} \text { - 류호경 }{ }^{2 \dagger}
\end{gathered}
$$

1)부산대학교 생활환경대학 식품영양학과, 대학원생, ${ }^{2}$ 부산대학교 생활환경대학 식품영양학과; 부산대학교 생활환경연구소, 교수

\title{
Analysis of Factors Affecting Breakfast Eating Behavior of Children in Indonesia: An Application of the Health Belief Model
}

\author{
Ran Yi Kang ${ }^{1)}$, Soo Jin Lee ${ }^{1)}$, Ho Kyung Ryu $\left.{ }^{2}\right)^{\dagger}$ \\ ${ }^{1)}$ Department of Food Science and Nutrition, Pusan National University, Busan, Korea, Graduate Student \\ ${ }^{2)}$ Department of Food Science and Nutrition, Pusan National University, Research Institute of Ecology, Busan, Korea, Professor
}

\section{${ }^{\dagger}$ Corresponding author Ho Kyung Ryu \\ Department of Food Science and Nutrition, Pusan National University, 2, Busandaehak-ro 63beon-gil, Geumjeong-gu, Busan 46241, Korea}

Tel: (051) 510-7397

Fax: (051) 583-3648

E-mail: hokryu@pusan.ac.kr

Received: August 20, 2019

Revised: January 29, 2020

Accepted: January 30, 2020

\section{ABSTRACT}

Objectives: This study investigates the current state of consuming breakfast among elementary school students residing in Malang, East Java, Indonesia, and to identify factors that influence breakfast behavior.

Methods: The research model was set up as per the health belief model, and slightly modified by adding the subjective normative factors of the theory of planned behavior. The survey was conducted from July 17 to August 15, 2017 using a questionnaire, after receiving the permission PNU IRB (2017_60_HR).

Results: The subjects were 77 boys (49.4\%) and 79 girls $(50.6 \%)$ suffering from malnutrition with anemia (21.2\%) and stunting ratio of Height for Age Z Score (HAZ) (11.5\%). Furthermore, moderate weakness (14.8\%) and overweight and obesity (12.3\%) by Body Mass Index for Age Z Score (BMIZ) were coexistent. According to the results obtained for breakfast, $21.8 \%$ did not eat breakfast before school, with $18.8 \%$ of the reasons for skipping breakfast being attributed to lack of food. Even for subjects partaking breakfast, only about $10 \%$ had a good balanced diet. The average score of behavioral intention on eating breakfast was $2.60 \pm 0.58$. The perceived sensitivity, perceived severity, perceived benefits, and self-efficacy of the health belief model correlated with breakfast behavior. Of these, self-efficacy $\left(\beta=0.447, \mathrm{R}^{2}=0.200\right)$ and perceived sensitivity $\left(\beta=0.373, R^{2}=0.139\right)$ had the greatest effect on breakfast behavior. Mother was the largest impact person among children.

Conclusions: In order to increase the level of breakfast behavior intention among children surveyed in Indonesia, we determined the effectiveness by focus on education which helps the children recognize to be more likely to get sick when they don't have breakfast, and increase their confidence in ability to have breakfast on their own. We believe there is a necessity to seek ways to provide indirect intervention through mothers, as well as impart direct nutrition education to children.

Korean J Community Nutr 25(1): 1 12, 2020

KEY WORDS breakfast eating behavior, health beliefs model, Indonesia, elementary school students

This is an Open-Access article distributed under the terms of the Creative Commons Attribution Non-Commercial License (http:// creativecommons.org/licenses/by-nc/3.0) which permits unrestricted non-commercial use, distribution, and reproduction in any medium, provided the original work is properly cited. 


\section{서 론}

건강한 아침식사는 건강하고 활동적이며 지적인 삶을 실 현하기 위한 균형 잡힌 영양 행동의 하나로, 이는 오전 9시 이전에 영양 필요의 15 30\%를 충족시키는 안전하고 영양 적인 식습관이다[1]. 특별히 학령기는 아동의 성장과 발달 이 일어나고 평생 건강의 밑거름이 되는 식습관을 형성하는 시기이므로 [2], 이 시기의 아침식사는 매우 중요하다. 규칙 적인 아침 식사는 성장하는 어린이와 청소년에게 영양권장 사항을 충족하고 [3], 몸을 튼튼하고 건강하게 유지할 수 있 게 해준다 [4]. 또한 학문에 대한 기억력과 열정을 향상시키 고, 아이들을 똑똑하고 명랑하게 만들며, 수면과 식사, 간식 을 예방하는 등의 많은 이점을 가진다 [5]. 반면 아침을 먹지 않는 경우 학생들의 학습에 악영향을 미치고, 신체활동을 감 소시키며, 건강에 좋지 않은 간식의 섭취 위험을 증가시킨다 는 연구결과가 있다[1]. 따라서 초등학생의 아침식사 습관 은 개인의 건강뿐 아니라 사회적으로도 매우 중요하다고 볼 수 있다.

2008년 인도네시아 보건부의 기초건강연구 자료에 따르 면, 5 12세 아동의 저신장 비율은 평균 $30.7 \%$ 이었고, 저 체중 비율은 평균 $11.2 \%$ 이었다. 반면 과체중과 비만은 각각 $10.8 \%$ 와 $8.0 \%$ 로 저체중인 아동보다 과체중 - 비만인 아동 이 더 많은 것으로 나타났다 [6]. 게다가 청소년 (10 19세) 들을 대상으로 한 연구에서 나이가 들수록 저체중은 줄어들 고, 과체중이 늘어나는 것으로 보고되어 [7], 영양결핍에 의 한 저신장 및 저체중의 문제와 열량과잉으로 인한 과제중과 비만의 문제가 동시에 발생하고 있음을 알 수 있다. 아침식 사를 거르는 사람들이 아침을 규칙적으로 먹는 사람들에 비 해 체질량지수가 유의하게 높고, 청소년과 성인의 비만을 유 발하며 인구통계학적 변수를 제외하여도 과체중의 위험이 $51 \%$ 더 높은 것으로 나타났다는 연구결과 $[1,8,9]$ 를 감안 한다면 아침식사의 중요성은 더욱 부각된다.

아동의 성장발육 정도를 확인하는 방법으로는 연령별 신 장의 Z-score (Height for Age Z Score: HAZ), 연령 별 체중의 Z-score(Weight for Age Z Score: WAZ), 신장별 체중의 Z-score(Weight for Height Z Score: WHZ) 및 연령별 체질량지수의 Z-score(Body Mass Index for Age Z Score: BMIZ) 등이 있다[10, 11]. $\mathrm{HAZ}$ 는 일반적으로 장기적인 영양실조 또는 발육부진 등의 만성 영양상태를 잘 나타내는 지표이고, $\mathrm{WAZ}$ 는 장기적, 단 기적 성장상태를 동시에 나타내는 지표이지만 신장에 대한 고려가 되지 않는 점이 있으며, $\mathrm{WHZ}$ 는 신장에 비하여 체중
이 어느 정도인지를 나타내는 것으로, 보다 단기적인 성장상 태를 반영하는 지표이다. 하지만 이 또한 나이에 대한 고려 가 되지 않는 점이 있어 [10], 2000년 CDC 성장지표에서 는 2 세 이상 대상 $\mathrm{BMIZ}$ 를 제공하여 나이에 따른 신장과 체 중의 관계 (체질량지수)를 나타내는 지표를 권장하고 있다 [12].

선행 연구결과에 따르면, 2002년부터 2011년까지 인도 네시아의 학령기 아동의 $16.9 \sim 59 \%$ 가 아침을 거르는 것으 로 나타났으며, 인도네시아 영양권장량의 $15 \%$ 보다 낮은 아 침식사를 하는 아동이 아동 인구의 $44.6 \%$ 인 것으로 나타났 다 [13] . 서부 자바(West Java)의 어린이들의 경우 전체 에 너지 섭취의 $40 \%$ 를 간식으로 섭취하는 것으로 나타났으며 비타민 A, C 및 칼슘의 섭취가 낮았고, 미량영양소도 인도네 시아 평균 영양권장량의 $60 \%$ 미만인 것으로 나타났다. 또한 7세 이상 아동에서 간식을 많이 섭취하는 그룹이 적게 섭취 하는 그룹보다 HAZ가 유의적으로 낮은 것으로 나타났다 [14].

아침결식은 아동들의 행동 변화로도 개선이 가능한 부분 으로 판단된다. 하지만 거의 모든 개발도상국에서 청소년 건 강행동에 대한 조사와 연구는 매우 부족한 실정이다. 인도네 시아도 예외는 아니어서 보건영양교육이 학교 프로그램으로 실시되고 있지만 정규과정에 포함되지 못하고 스포츠, 가정 학 등 다양한 과목의 일부로 제공되어 그 중요성이 낮다. 또 한 전문 영양교사나 보건교사가 체계적으로 교육을 하는 곳 은 거의 없고 전문교육을 받은 적이 없는 일반교사가 진행하 거나 일정 기간 교육을 받은 자원봉사자에 의해 일시적으로 이루어지는 교육이 대부분이다. 이러한 교육이 그동안 학생 들의 지식과 태도에는 일부 영향을 미쳤으나 행동 변화와 실 천에는 영향을 미치지 못한 것으로 나타났다[15].

건강신념모델을 기초로 아침식사 식행동에 관한 연구는 전 세계적으로 매우 드믄 실정이다. 국내에서는 건강신념모델 을 이용한 전통 식생활에 대한 인식조사 결과 자신의 식생활 과 관련한 질병 위협에 대한 인식은 높지 않았으나 전통 식 생활 실천에 대한 이득과 자아효능감은 높고 장애요인에 대 한 인식은 낮은 것으로 나타났다[16]. 또한 남자 대학생을 대상으로 건강신념모델에 근거한 영양교육을 통해 일상생활 에 스스로 적용할 수 있는 식생활 태도 변화를 야기하고자 하 였는데 교육 실시 후에 식습관의 교정이 질병을 예방할 수 있 다는 관심도가 증가하였다[17]. 국외에서는 초등학생의 건 강에 좋지 않은 과자 소비를 줄이기 위해 건강신념모델을 이 용한 영양교육에서, 전과 후에 실험군에서 건강신념모델의 인지된 민감성, 인지된 심각성, 인지된 이득의 점수가 유의적 으로 증가하였고, 인지된 장애는 감소하는 결과를 보였다 [18]. 이에 본 연구는 인도네시아 아동의 건강장애의 원인 중 하 나로 생각되는 아침식사 행동의 변화를 유도하기 위해 건강 


\section{Health Belief (A1)}

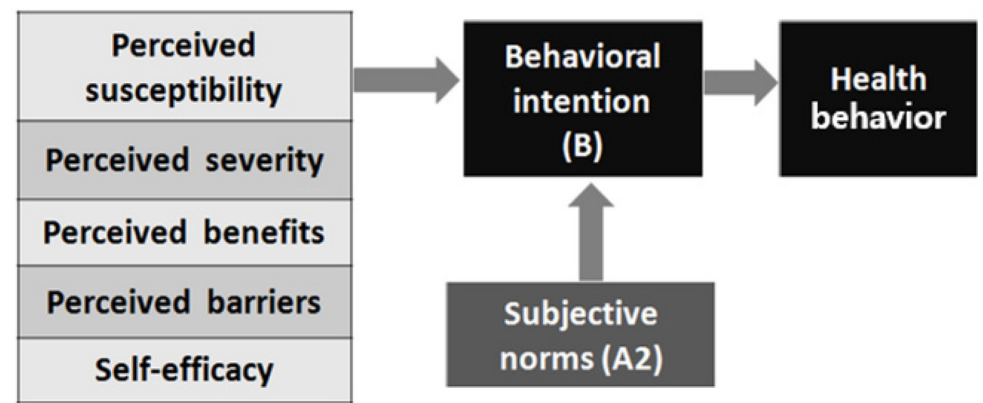

Fig. 1. The study model based on health belief model and theory of planned behavior

신념모델에 계획적 행동이론의 주관적 규범을 추가한 이론 적 연구모형 (Fig. 1)에 근거하여 아침식사하기 행동에 영향 을 미치는 요인을 파악하고자 실시되었다.

\section{연구대상 및 방법}

\section{1. 조사대상}

인도네시아 어린이들의 아침식사하기 행동에 영향을 미치 는 요인을 살펴보기 위해 인도네시아 동부 자바 지역 말랑 (Malang)시의 초등학생을 대상으로 설문조사를 실시하였 다. 이는 동부 자바 지역이 인도네시아에서 0 17세 아동인 구가 차지하는 비율이 두 번째로 높은 지역이라는 자료에 근 거하였다 [19]. 또한 자기 기입식 설문조사임을 감안하여 초 등학교 4 6학년 학생으로 조사 대상을 한정하였다. 조사대 상자의 수는 G*Power 3.1.92 for Windows를 사용하여 산정한 후 탈락률을 고려하여 총 160 명으로 정하여 조사를 실시하였다. 이중 불성실한 응답지 4 부를 제외한 남학생 77 명, 여학생 79 명 등 총 156 명의 응답지를 분석에 사용하였 다. 본 연구는 부산대학교 생명윤리위원회 (IRB)의 승인 (PNU IRB/2017_60_HR)을 받은 후 2017년 7월 17일부터 8월 24 일까지 6차례에 걸쳐 조사를 시행하였다.

\section{2. 조사 내용 및 분석 방법}

\section{1) 설문지 구성}

설문은 선행 연구 [20-22]를 참고하여 문항을 작성한 후 인도네시아어로 번역하였고, 조사대상자의 이해에 어려움이 없도록 해당 지역 현지인의 자문을 구하여 완성하였다. 조사 대상자가 초등학생임을 고려하여 이해하는 데 어려움이 없 도록 가능한 쉬운 단어를 사용하였다. 설문은 대상자의 일반 적 사항 8 문항, 아침식사 실태 6 문항, 아침식사하기 행동의
도를 예측하기 위한 건강신념모델 15 문항, 아침식사하기 행 동의도를 묻는 설문 3 문항, 주관적 규범 10 문항 등 총 42 문 항으로 구성하였다. 건강신념모델의 15 문항은 3 단계의 리 커트 (Likert) 척도로 대답하게 하였고, '그렇게 생각하지 않 는다' 1점, ‘보통이다' 2점, ‘그렇게 생각한다' 3점으로 환산 하여 점수를 제시하였다. 주관적 규범을 측정하기 위한 준거 집단으로는 아버지, 어머니, 선생님, 친구, 형제자매를 제시 하였다.

\section{2) 신체계측 및 헤모글로빈 측정}

정확한 신체계측과 혈액검사를 위하여 이동형 신장계 (Seca 213 portable height measure, seca gmbh \& co. kg., Hamburg, Germany), 체중계 (Omron body composition monitor $\mathrm{HBF}-214-\mathrm{W}$, Krell precision Co. Ltd., Yangzhou, China) 및 휴대용 헤모글로빈 측정기 (BeneCheck Hb Hemoglobin Meter, General Life Biotechnology Co. Ltd., New Taipei, Taiwan)를 이용 해 연구자가 직접 신장과 체중, 헤모글로빈 농도를 측정한 후 바로 설문지에 기입하였다.

\section{3) 성장발 육상태 분석}

본 연구에서는 조사 대상자의 성장발육 정도를 확인하고, 여러 변수와의 관계분석을 위해 장기적 영양상태 (발육부진) 를 확인할 수 있는 지표인 HAZ와 단기적 영양상태 (허약 또 는 과체중, 비만)를 확인할 수 있는 지표인 BMIZ를 사용하 였다. 조사 대상자들의 두 가지 성장발육 지수에 따라 만성 영양장애 (발육부진)는 중증 발육부진 $(\mathrm{HAZ}<-3 \mathrm{SD})$, 중 등도 발육부진 $(-3 \mathrm{SD} \leq \mathrm{HAZ}<-2 \mathrm{SD})$, 정상 $(-2 \mathrm{SD} \leq$ $\mathrm{HAZ} \leq 2 \mathrm{SD}$ )으로 분류하였고, 급성영양장애 (허약/비만) 는 중증 허약 $(\mathrm{BMIZ}<-3 \mathrm{SD})$, 중등도 허약 $(-3 \mathrm{SD} \leq$ 
$\mathrm{BMIZ}<-2 \mathrm{SD})$, 정상 $(-2 \mathrm{SD} \leq \mathrm{BMIZ} \leq 1 \mathrm{SD})$, 과체중 $(1 \mathrm{SD}<\mathrm{BMIZ} \leq 2 \mathrm{SD})$, 비만 $(2 \mathrm{SD}<\mathrm{BMIZ})$ 으로 분류하 였다.

\section{4) 통계분석}

본 조사의 모든 자료는 IBM SPSS Statistics 23 (IBM Corporation, Armonk, NY, USA)을 이용하여 분석하였 다. 조사된 자료의 분석을 위해 빈도분석 및 평균과 표준편 차 등 기본적인 기술통계를 실시하였고, 군 간의 비교를 위 해 교차분석 및 Student's t-test를 실시하였다. 기대값 이 5 미만인 셀이 $20 \%$ 이상인 경우는 Fisher's exact test를 실시하였다. 아침식사하기 행동의도에 영향을 미치 는 요인을 규명하기 위해 건강신념모델의 모든 항목들 및 주관적 규범과 행동의도와의 상관관계분석을 실시하였고, 변인들 간의 상관관계가 확인된 경우, 선형 회귀분석을 실 시하였다.

\section{결 과}

\section{1. 연구대상자의 일반적 사항}

조사 대상자의 일반적 사항은 Table 1과 같다. 조사에 참 여한 전체 156 명 중 남학생은 77 명 $(49.4 \%)$, 여학생은 79 명 (50.6\%)이었고, 연령은 10세 (51명, 32.7\%), 11세 (57 명, $36.5 \%$ ) 및 12 세 (30명, $19.2 \%$ )가 대부분이었다. 종족 은 조사지역 특성상 자바족이 96.2\%(150명)를 차지하였 다. 식사는 주로 어머니 (88.5\%)가 준비하였고 조모 $(13.5 \%)$ 가 준비하는 경우도 있었다. 부모의 최종학력에서 아버지의 학력은 고졸 $(28.2 \%)$, 초졸 (19.9\%), 중졸 $(15.4 \%)$ 의 순이 었고, 어머니의 학력은 중졸 $(26.9 \%)$, 고졸 $(23.1 \%)$, 초졸 (17.9\%)의 순으로 비교적 낮은 편이었으며, 응답을 하지 않 은 대상자도 각각 $24.4 \%$ 와 25\%로 높게 나타났다. 경제적 인 형편에 대한 질문에 조사대상자 대부분인 $135(86.5 \%)$ 명이 ‘보통’으로 응답하였다.

\section{2. 연구대상자의 신체계측 및 혈액 검사 1) 체위, 성장발육 및 빈혈 실태}

조사 대상자의 신체계측 결과는 Table 2 와 같다. 남아는 평균 신장 $136.8 \mathrm{~cm}$ 에 체중 $31.8 \mathrm{~kg}$ 이었고, 여아는 평균 신장 $141.5 \mathrm{~cm}$ 에 체중 $33.2 \mathrm{~kg}$ 로 나타났다. 체위를 기준 으로 조사 대상자들을 성장발육 지수에 따라 분류하였다. $\mathrm{HAZ}$ 분류에서 중증 발육부진에 해당하는 아동은 없었으나 중등도 발육부진으로 분류되는 아동 비율이 $11.5 \%$ 나 되었 고, 남아 $(18.2 \%)$ 가 여아 $(5.1 \%)$ 보다 발육 부진률이 유의적
Table 1. General characteristics of subjects

\begin{tabular}{|c|c|c|}
\hline \multicolumn{2}{|l|}{ Variables } & Frequency \\
\hline \multirow[t]{2}{*}{ Gender } & Boys & $77(49.4)$ \\
\hline & Girls & $79(50.6)$ \\
\hline \multirow[t]{5}{*}{ Age } & 9 & $14(9.0)$ \\
\hline & 10 & $51(32.7)$ \\
\hline & 11 & $57(36.5)$ \\
\hline & 12 & $30(19.2)$ \\
\hline & 13 or over & $4(2.6)$ \\
\hline \multirow[t]{2}{*}{ Tribe } & Java & $150(96.2)$ \\
\hline & The Others & $6(3.8)$ \\
\hline \multirow[t]{5}{*}{ Main meal preparation } & Grandfather & $2(1.3)$ \\
\hline & Grandmother & $21(13.5)$ \\
\hline & Father & $6(3.8)$ \\
\hline & Mother & $138(88.5)$ \\
\hline & Brothers and sisters & $1(6.0)$ \\
\hline \multirow[t]{6}{*}{ Father's education level } & College & $14(9.0)$ \\
\hline & High school & $44(28.2)$ \\
\hline & Middle school & $24(15.4)$ \\
\hline & Elementary school & $31(19.9)$ \\
\hline & No school & $2(1.3)$ \\
\hline & Non-response & $38(24.4)$ \\
\hline \multirow[t]{6}{*}{ Mother's education level } & College & $7(4.5)$ \\
\hline & High school & $36(23.1)$ \\
\hline & Middle school & $42(26.9)$ \\
\hline & Elementary school & $28(17.9)$ \\
\hline & No school & $1(0.6)$ \\
\hline & Non-response & $39(25.0)$ \\
\hline \multirow[t]{4}{*}{ Economic status } & High & $2(1.3)$ \\
\hline & Medium & $135(86.5)$ \\
\hline & Low & $2(1.3)$ \\
\hline & Non-response & $17(10.9)$ \\
\hline \multicolumn{2}{|c|}{ Total } & 156 (100.0) \\
\hline
\end{tabular}

$\mathrm{n}(\%)$

으로 높은 것으로 나타났다. BMIZ 분류에서는 남녀 간의 유 의적인 차이는 없었으나, 중증허약과 중등도 허약으로 분류 되는 아동 비율이 $14.7 \%$, 과체중과 비만으로 분류되는 아동 비율이 $12.2 \%$ 로, 과체중 보다는 허약한 아동의 비율이 더 높은 것으로 나타났다.

빈혈은 혈색소의 감소로 나타나는데 WHO 진단기준 [23] 과 인도네시아 국가기초보건연구 [7]에 의해 5 12세 아동 의 경우 헤모글로빈 $12.0 \mathrm{~g} / \mathrm{dL}$ 미만을 빈혈로 진단하였다. 그 기준에 따라 조사 대상자의 빈혈 여부를 진단한 결과, 전 체 아동 중 $21.2 \%$ 의 아동이 빈혈인 것으로 확인되었고, 남 아 전체 중 $23.4 \%$ 가, 여아 전체 중 $19.0 \%$ 가 빈혈인 것으로 나타났다. 
Table 2. Growth and development status and anemia of the subjects

\begin{tabular}{|c|c|c|c|c|c|}
\hline & Variables & Boys & Girls & Total & $\operatorname{tor} \chi^{2}$ \\
\hline \multicolumn{6}{|c|}{ Anthtropometric status } \\
\hline \multicolumn{2}{|l|}{ Height (cm) } & $136.8 \pm 7.5$ & $141.5 \pm 6.5$ & $139.1 \pm 7.0$ & $0.003 * *$ \\
\hline \multicolumn{2}{|l|}{ Weight (kg) } & $31.8 \pm 7.2$ & $33.2 \pm 6.9$ & $32.5 \pm 7.0$ & 0.366 \\
\hline \multicolumn{6}{|c|}{ Growth and development status } \\
\hline \multirow[t]{3}{*}{$H A Z^{\prime \prime}$} & Severe stunting & $0(0.0)$ & $0(0.0)$ & $0(0.0)$ & $6.574 *$ \\
\hline & Moderate stunting & $14(18.2)$ & $4(5.1)$ & $18(11.5)$ & \\
\hline & Normal & $63(81.8)$ & $75(94.9)$ & $138(88.5)$ & \\
\hline \multirow[t]{5}{*}{$\mathrm{BM} I \mathrm{Z}^{2)}$} & Severe weakness & $2(2.6)$ & $3(3.8)$ & $5(3.2)$ & 0.844 \\
\hline & Moderate weakness & $9(11.7)$ & $9(11.4)$ & $18(11.5)$ & \\
\hline & Normal & $55(71.4)$ & $59(74.7)$ & $114(73.1)$ & \\
\hline & Overweight & $10(13.0)$ & $7(8.9)$ & $17(10.9)$ & \\
\hline & Obesity & $1(\quad 1.3)$ & $1(1.3)$ & $2(1.3)$ & \\
\hline \multicolumn{6}{|l|}{ Anemia } \\
\hline \multicolumn{2}{|l|}{ Anemia } & $18(23.4)$ & $15(19.0)$ & $33(21.2)$ & 0.883 \\
\hline \multicolumn{2}{|l|}{ Normal } & $59(76.6)$ & $64(81.0)$ & $123(78.8)$ & \\
\hline \multicolumn{2}{|l|}{ Total } & 77 (100.0) & $79(100.0)$ & $156(100.0)$ & \\
\hline
\end{tabular}

$\mathrm{n}(\%)$ or Mean $\pm \mathrm{SD}$

$* P<0.05, * * P<0.01$ by student's t-test or $\chi^{2}$ test

1) Height for Age $Z$ score

2) BMl for Age Z score

\section{3. 아침식사 실태}

조사 대상자의 아침식사에 대한 실태는 Table 3 과 같다. 등교 전 아침식사를 매일한다고 응답한 아동은 $62.8 \%$ 였으 며, 거의 먹지 않는 비율이 $21.8 \%$ 로 높은 비율을 차지하였 다. 아침결식을 하는 경우, 결식의 이유를 모두 선택하라는

Table 3. Breakfast eating status of subjects

\begin{tabular}{|c|c|}
\hline Eating status & Frequency \\
\hline \multicolumn{2}{|l|}{ Frequency } \\
\hline Everyday & $98(62.8)$ \\
\hline About once every two days & $24(15.4)$ \\
\hline Hardly eat & $34(21.8)$ \\
\hline Total & $156(100.0)$ \\
\hline \multicolumn{2}{|l|}{ Reasons for skipping") } \\
\hline Nothing to eat & $12(18.8)$ \\
\hline No one to prepares meals & $2(3.1)$ \\
\hline No time to eat & $18(28.1)$ \\
\hline Poor appetite & $17(26.6)$ \\
\hline Do not want to eat & $15(23.4)$ \\
\hline Total & $64(100.0)$ \\
\hline \multicolumn{2}{|l|}{ How to manage hunger") } \\
\hline Home-made lunch box & $33(45.8)$ \\
\hline Buy a meal around school & $21(29.2)$ \\
\hline Snack & $6(8.3)$ \\
\hline The others & $12(16.7)$ \\
\hline Total & $72(100.0)$ \\
\hline
\end{tabular}

1) Multiple response was allowed
Table 4. Types of foods for breakfast

\begin{tabular}{|c|c|}
\hline Types of foods & Frequency \\
\hline Carbohydrates'1) & $39(25.6)$ \\
\hline Meat and fish & $4(2.6)$ \\
\hline Vegetables & $29(18.6)$ \\
\hline Fruits & $2(1.3)$ \\
\hline Beverage & $2(1.3)$ \\
\hline Carbohydrates + meat and fish & $11(7.1)$ \\
\hline Carbohydrates + meat and fish + beverage & $3(1.9)$ \\
\hline Carbohydrates + meat and fish + vegetables & $3(1.9)$ \\
\hline $\begin{array}{l}\text { Carbohydrates }+ \text { meat and fish }+ \text { vegetables }+ \\
\text { beverage }\end{array}$ & $7(4.5)$ \\
\hline $\begin{array}{l}\text { Carbohydrates }+ \text { meat and fish }+ \text { vegetables }+ \\
\text { fruits }+ \text { beverage }\end{array}$ & $6(3.8)$ \\
\hline Carbohydrates + vegetables & $11(7.1)$ \\
\hline Carbohydrates + vegetables + fruits & $3(1.9)$ \\
\hline Carbohydrates + vegetables + beverage & $9(5.8)$ \\
\hline Carbohydrates + vegetables + fruits + beverage & $1(0.6)$ \\
\hline Carbohydrates + fruits & $4(2.6)$ \\
\hline Carbohydrates + beverage & $14(9.0)$ \\
\hline Meat and fish + beverage & $7(4.5)$ \\
\hline Ratio of single-food meal & $49.4 \%$ \\
\hline Ratio of balanced meal & $10.2 \%$ \\
\hline Ratio of intakes of meat and fish & $26.3 \%$ \\
\hline Total & $156(100.0)$ \\
\hline
\end{tabular}


질문에서는 '시간이 없어서(28.1\%)', '입맛이 없어서 (26.6\%)', '먹어야한다는 생각이 없어서 (23.4\%)', '먹을 것이 없어서 (18.8\%), 순으로 응답하였다. 아침결식 후, 배 고픔을 해결하는 방법을 모두 선택하라는 질문에서는 '집에 서 가져 온 도시락을 먹는다’가 $45.8 \%$ 로 가장 많았고, ‘학교 나 근처에서 사 먹는다 (29.2\%)'가 많은 비율을 나타내었다.

아침식사로 섭취하는 음식은 Table 4와 같다. 아침식사로 섭취한 식품의 종류를 모두 고르도록 한 결과 상당수 $(49.4 \%)$ 가 단일식품만으로 아침식사를 해결하는 것으로 나타났다. 조사대상자의 $10.2 \%$ 만이 비교적 균형적인 식사인 '탄수화 물’, ‘육류 및 생선류’, ‘채소류’를 포함한 식사를 하는 것으 로 나타났으며, ‘육류 및 생선류’를 섭취한 비율은 $26.3 \%$ 에 불과하였다.

\section{4. 아침식사 행동에 영향을 미치는 요인 \\ 1) 아침식사하기 행동의도}

아침식사하기의 행동의도 점수는 Table 5 와 같다. 제시한 3 문항 중 아침식사를 할 때 영양을 생각해 골고루 섭취할 것
이다'는 항목 (2.73 \pm 0.50$)$ 의 점수가 가장 높았고, '나는 아 침식사하기를 습관화 할 것이다(2.60 \pm 0.60$)$ ', '건강을 위 해 아침에 더 일찍 일어나 아침식사를 하고 등교할 것이다 (2.47 \pm 0.66$)$ '순으로 나타났으며 3 문항 평균은 $2.60 \pm$ 0.58 이었다.

\section{2) 건강신념 요인의 항목별 비교}

건강신념모델의 각 요인의 항목별 점수는 Table 6 와 같 다. 요인들 중 '인지된 이득 ( $2.78 \pm 0.43)$ '이 가장 높은 점 수를 보여 아침식사하기 행동이 변화되면 긍정적인 결과가 올 것이라는 기대효과가 가장 크다는 것을 알 수 있었다. '인 지된 이득' 중에서는 ‘아침을 꾸준히 먹으면 성장에 도움이 된다'는 항목 (2.85 \pm 0.35 )이 가장 높은 점수를 나타냈다.

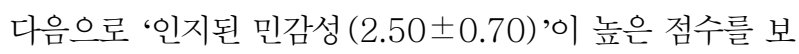
여 아침식사를 하지 많으면 자신이 질병이나 장애에 노출될 가능성이 높아질 것이라는 생각을 가지고 있었으며, '인지된 민감성' 중에서는 ‘오랫동안 배가 고프면 아플 수 있다'라는 항목의 점수가 가장 높게 나타났다. 다음으로 자아존중감, 인

Table 5. Behavioral intention on eating breakfast

\begin{tabular}{|c|c|c|c|}
\hline \multirow{2}{*}{$\frac{\text { Construct }}{\text { Behavioral intention }}$} & \multirow{2}{*}{$\begin{array}{l}\text { Measurement questions } \\
\text { I will wake up earlier in the morning to eat breakfast for my health and go to school. }\end{array}$} & \multicolumn{2}{|c|}{ Scores } \\
\hline & & $2.47 \pm 0.66$ & $2.60 \pm 0.58^{11}$ \\
\hline & I will make it a habit to eat breakfast. & $2.60 \pm 0.60$ & \\
\hline & I will eat breakfast evenly for the sake of nutrition. & $2.73 \pm 0.50$ & \\
\hline
\end{tabular}

Mean \pm SD

Scoring criteria : 'I don't think so' 1 point, 'I think it's normal' 2 point, 'I think so' 3 point

1) Average of 3 questions

Table 6. Health beliefs on eating breakfast

\begin{tabular}{llll}
\hline \multicolumn{1}{c}{ Health beliefs } & \multicolumn{1}{c}{ Measurement questions } & Scores \\
\hline Perceived susceptibility & If you skip breakfast, you will not feel cheerful and dizzy & $2.46 \pm 0.71$ & $2.50 \pm 0.70^{1)}$ \\
& If you are hungry for a long time, you can be sick. & $2.53 \pm 0.70$ \\
& If you do not eat breakfast, you may lose concentration. & $2.51 \pm 0.70$ \\
Perceived severity & I think that obesity caused by snacking can be life-threatening. & $2.33 \pm 0.74$ & $2.43 \pm 0.70$ \\
& I think severe anemia prevents proper growth. & $2.42 \pm 0.71$ \\
& Chronic malnutrition is thought to reduce cognitive ability and brain function. & $2.56 \pm 0.67$ \\
Perceived benefits & When you eat breakfast, you feel better. & $2.67 \pm 0.52$ & $2.78 \pm 0.43$ \\
& If you eat breakfast, you can study well. & $2.83 \pm 0.42$ \\
Perceived barriers & If you eat breakfast consistently, it will help you grow. & $2.85 \pm 0.35$ \\
& I usually do not have enough food to eat breakfast at home. & $2.18 \pm 0.75$ & $2.31 \pm 0.72$ \\
& There is no one to prepare breakfast, nor does it prepare. & $2.48 \pm 0.70$ \\
Self-efficacy & There is not enough time to get breakfast before school. & $2.20 \pm 0.70$ \\
& I am afraid that eating breakfast every day will make me fat. & $2.41 \pm 0.74$ \\
\hline
\end{tabular}

Mean \pm SD

Scoring criteria : 'I don't think so' 1 point, 'I think it's normal' 2 point, 'I think so' 3 point

1) Average of questions 
지된 심각성의 순으로 점수가 높았으며 ‘인지된 장애 (2.31 $\pm 0.72)^{\prime}$ 는 가장 낮은 점수를 보여 아침식사를 하는데 있어 서의 장애요인들은 그다지 큰 문제가 되지 않는 것으로 나타 났다.

\section{3) 주관적 규범의 항목별 비교}

주관적 규범의 두 가지 요인인 규범적 신념과 순응동기의 영향력을 비교한 결과는 Table 7과 같다. 규범적 신념에서

Table 7. Subjective norms on eating breakfast

\begin{tabular}{|c|c|}
\hline Measurement questions of each construct & Scores \\
\hline \multicolumn{2}{|l|}{ Normative belief } \\
\hline If I eat breakfast, my father will encourage me. & $2.62 \pm 0.61$ \\
\hline If I eat breakfast, my mother will encourage me. & $2.64 \pm 0.60$ \\
\hline If I eat breakfast, my teacher will encourage me. & $2.57 \pm 0.63$ \\
\hline If I eat breakfast, my friend will encourage me. & $2.28 \pm 0.70$ \\
\hline If I eat breakfast, my brother or sister will encourage me. & $2.47 \pm 0.65$ \\
\hline \multicolumn{2}{|l|}{ Motivation to comply } \\
\hline If my father encourage me, I will have breakfast. & $2.19 \pm 0.79$ \\
\hline If my mother encourage me, I will have breakfast. & $2.24 \pm 0.79$ \\
\hline If my teacher encourage me, I will have breakfast. & $2.07 \pm 0.81$ \\
\hline If my friend encourage me, I will have breakfast. & $2.00 \pm 0.79$ \\
\hline $\begin{array}{l}\text { If my brother or sister encourage me, I will have } \\
\text { breakfast. }\end{array}$ & $2.15 \pm 0.76$ \\
\hline \multicolumn{2}{|l|}{ Subject norms } \\
\hline Father & $5.85 \pm 2.64$ \\
\hline Mother & $6.02 \pm 2.71$ \\
\hline Teacher & $5.44 \pm 2.69$ \\
\hline Friend & $4.66 \pm 2.54$ \\
\hline Brother \& sister & $5.42 \pm 2.57$ \\
\hline
\end{tabular}

Mean \pm SD

Scoring criteria : 'I don't think so' 1 point, 'I think it's normal' 2 point, 'I think so' 3 point
는 어머니의 규범적 신념 $(2.64 \pm 0.60)$ 이 가장 높게 나타났 으며, 다음으로 아버지 (2.62 \pm 0.61$)$, 선생님 $(2.57 \pm 0.63)$ 의 순이었다. 순응동기도 어머니 (2.24 \pm 0.79$)$ 가 가장 높게 나타났으며, 다음으로 아버지 (2.19 \pm 0.79$)$ 와 형제자매 (2.15 $\pm 0.76)$ 의 순으로 나타났다. 이는 조사대상 아동들은 어머 니가 가장 아침식사 하는 것을 격려할 것이라고 생각하고 있 으며, 또한 어머니의 뜻을 받아들일 의사도 가장 높음을 보 여주었고, 이에 따라 주관적 규범값도 어머니가 가장 높은 값 을 나타내었다.

\section{4) 건강신념 및 주관적 규범과 행동의도의 상관성}

건강신념 요인들과 주관적 규범이 아침식사하기 행동의도 와 관련이 있는지 상관관계를 분석한 결과는 Table 8 과 같 다. 건강신념 다섯 가지 요인 중 인지된 장애를 제외한 네 가 지 요인이 모두 상관관계를 나타내었다. 주관적 규범도 행동 의도에 정적인 상관성이 있음을 보여 주었다.

\section{5) 건강신념 및 주관적 규범이 행동의도에 미치는 영향}

건강신념 중 어떤 요인이 행동의도에 영향을 미치는지 회 귀분석을 한 결과는 Table 9 와 같다, 자기 효능감 $(\beta=0.447$, $P<0.001)$ 과 인지된 민감성 $(\beta=0.373, P<0.001)$ 이 행 동의도에 높은 정 $(+)$ 적 영향을 미치는 것으로 확인되었으 며, 각각 $20 \%$ 와 $13.9 \%$ 의 높은 설명력을 보였다. 인지된 이 득 $(\beta=0.302, P<0.001)$ 과 인지된 심각성 ( $\beta=0.231, P$ $<0.01)$ 도 아침식사하기 행동의도에 정 $(+)$ 적인 영향을 미 치는 것으로 나타났으나, 설명력은 각각 $9.1 \%$ 와 $5.3 \%$ 로 다소 낮게 나타났다. 주관적 규범도 상관관계 분석에서 정 적 상관성이 나타나긴 하였으나 설명력이 $2 \%$ 정도로 매우 낮았다.

Table 8. Correlation between constructs of health beliefs, subject norms, or behavioral intention on eating breakfast

\begin{tabular}{|c|c|c|c|c|c|c|c|}
\hline & \multicolumn{7}{|c|}{ Pearson's correlation coefficients } \\
\hline & $\begin{array}{c}\text { Perceived } \\
\text { susceptibility }\end{array}$ & $\begin{array}{l}\text { Perceived } \\
\text { severity }\end{array}$ & $\begin{array}{l}\text { Perceived } \\
\text { benefits }\end{array}$ & $\begin{array}{l}\text { Perceived } \\
\text { barriers }\end{array}$ & Self-efficacy & $\begin{array}{l}\text { Behavior } \\
\text { intention }\end{array}$ & \\
\hline Perceived susceptibility & 1 & & & & & & \\
\hline Perceived severity & $0.620 * * *$ & 1 & & & & & \\
\hline Perceived benefits & $0.394 * * *$ & $0.409 * * *$ & 1 & & & & \\
\hline Perceived barriers & 0.069 & 0.007 & 0.064 & 1 & & & \\
\hline Self-efficacy & 0.109 & 0.109 & $0.361 * * *$ & 0.028 & 1 & & \\
\hline \multirow[t]{2}{*}{ Behavior intention } & $0.380 * * *$ & $0.264 * *$ & $0.395 * * *$ & 0.063 & $0.461 * * *$ & 1 & \\
\hline & & & & & & $\begin{array}{l}\text { Behavior } \\
\text { intention }\end{array}$ & $\begin{array}{c}\text { Subject } \\
\text { norms }\end{array}$ \\
\hline Behavior intention & & & & & & 1 & \\
\hline Subject norms & & & & & & $0.163^{*}$ & 1 \\
\hline
\end{tabular}

$* P<0.05, * * P<0.01, * * * P<0.001$ 
$8 \cdot$ 인도네시아 아동들의 아침식사 행동 영향 요인

Table 9. Association between health beliefs and behavioral intention on eating breakfast

\begin{tabular}{lccccc}
\hline \multirow{2}{*}{ Health beliefs } & \multicolumn{5}{c}{ Behavioral intention on eating breakfast } \\
\cline { 2 - 6 } & $R^{1)}$ & $R^{21}$ & F-value & $\beta^{4)}$ & t-value \\
\hline Self-efficacy & 0.447 & 0.200 & $38.260^{* * *}$ & 0.447 & $6.185^{* * *}$ \\
Perceived susceptibility & 0.373 & 0.139 & $24.943^{* * *}$ & 0.373 & $4.994^{* * *}$ \\
Perceived benefits & 0.302 & 0.091 & $15.338^{* * *}$ & 0.302 & $3.916^{* * *}$ \\
Perceived severity & 0.231 & 0.053 & $8.490^{* *}$ & 0.231 & $2.914^{* *}$ \\
Subject norms & 0.163 & 0.026 & 4.134 & 0.163 & $2.703^{*}$ \\
Perceived barriers & 0.090 & 0.008 & 1.238 & -0.090 & 1.113 \\
\hline
\end{tabular}

* $P<0.05, * * P<0.01, * * * P<0.001$

1) Correlation coefficient between independent variable and dependent variable

2) Coefficient of determination, indicating how many percent of the total variability can be explained by independent variables

3) Test statistic of significance of the regression model

4) Regression coefficient, influence of independent variables on dependent variables, the closer to 1 , the higher the influence

5) Test statistic of regression coefficient

\section{고 찰}

본 연구는 인도네시아 자바지역 Malang시의 초등학생을 대상으로 아침식사 실태를 조사하고, 영양교육의 이론을 적 용하여 아침식사하기 행동에 영향을 미치는 요인을 알아보 고자 실시하였다.

저체중 아동의 비율이 높은 국가들은 정상적인 신장으로 성장하지 못하는 발육부진의 문제와 아동의 신장 대비 저체 중의 문제를 격고 있다. 본 연구결과에서도 $\mathrm{HAZ}$ 분석에 의 하면 조사대장자 중 중등도 발육부진으로 분류되는 아동 비 율이 남녀 각각 $18.2 \%$ 와 $5.1 \%$ 로 높았으며, BMIZ 분류에 서도 중증 허약과 중등도 허약으로 분류되는 아동 비율이 $14.7 \%$, 과체중과 비만으로 분류되는 아동 비율이 $12.2 \%$ 로 나타났다. 인도네시아에서도 점차 허약한 아동에 비해 과체 중 아동의 비율이 계속 높아지는 추세라는 보고 [7]와는 차 이가 있는 것으로 보여진다. 그러나 2019년 인도네시아 Bogor지역의 도시와 농촌 초등학생을 비교한 연구에서 도 시에서는 발육부진은 $6.5 \%$ 이고 과체중은 $22.1 \%$ 로 과체중 의 비율이 높은데 비해 농촌지역은 발육부진이 $33.8 \%$ 로 매 우 높고 과체중은 $1.5 \%$ 에 불과하여 거주 지역 간에 큰 차이 를 보였다 [24]는 결과와 비교해볼 때 저체중 아동의 비율이 과체중과 비만 아동의 비율보다 높은 것은 조사지역이 도시 와 농촌의 특성을 함께 갖춘 소도시이기 때문인 것으로 생각 된다.

혈중 헤모글로빈 농도를 조사한 결과 조사대상자의 $21.2 \%$ 가 빈혈인 것으로 나타났다. 이는 2013년 인도네시아 전 지 역의 5 12세 아동의 빈혈 비율이 남아와 여아 모두 $29.4 \%$ 로 나타났던 선행연구 [7] 보다는 낮은 비율이었으나 여전히 높은 비율이다. 이는 영양결핍에 따른 한 현상으로 생각된
다. 세계식량기구 $(\mathrm{FAO})$ 의 자료에 의하면 총 인구대비 영양 결핍 발생률 (2006 2008년)이 인도네시아는 $13 \%$ 로 인근 아시아국가 중 캄보디아 $(25 \%)$ 보다는 낮으나 베트남 $(11 \%)$, 중국 $(10 \%)$ 보다는 높아서 [25] 영양결핍이 인도네시아의 중요한 문제임을 알 수 있다. $\mathrm{WHO}$ 의 세계보건보고서에 의 하면 전 세계 사망원인의 $1 / 3$ 이상이 10 가지 중대위험요인 때문이며, 그 중 7 가지 (저체중, 고혈압, 흡연, 알코올 섭취, 안전하지 않은 물, 위생, 철분결핍)는 영양상태와 연관이 있 는 것으로 나타나 [26], 본 연구에서의 높은 빈혈율 역시 철 분결핍에 의한 것이므로 영양결핍상태를 나타내는 지표가 될 수 있다.

아동의 아침식사실태 조사 결과 등교 전 아침식사 결식율 은 $21.8 \%$ 로 나타났다. 2013년에 실시한 인도네시아 Java 지역 전 연령대를 대상으로 한 연구에서 아침식사를 하지 않 는다,는 비율이 $16.8 \%$ 로 나타났고, 아침 결식율이 계속 증 가하는 추세라고 보고한 것 [27]은 본 조사에서의 높은 결식 율과도 관련이 있을 것으로 생각된다. 이 역시 지역 간의 차 이가 있어 인도네시아의 농촌지역 아동의 경우 일주일에 4 회 이상 아침식사를 하는 비율이 $58.5 \%$ 로 도시 아동의 88.3\%에 비해 유의적으로 낮았다는 보고도 있다 [24]. 아침 결식 아동의 수는 전 세계적으로도 높은 것으로 보고되고 있 다. 미국의 어린이와 청소년의 아침결식 비율은 약 $30 \%$ 에 달하는 것으로 나타났다 [28]. 또한 캐나다 [29], 아시아 [28, 30, 31], 유럽 여러 국가 [32-36]에서도 꾸준히 아동의 아 침식사 결식이 증가하고 있는 것으로 보고되고 있고, 말레이 시아 [30] 와 대만 [8] 에서는 약 $25 \%$ 전후의 어린이가 아침 식사를 불규칙하게 섭취하고 있는 것으로 나타났다. 그러나 본 조사 결과에서 주목해야 할 것은 높은 결식율 뿐 아니라 결식의 원인이다. 아침을 결식하는 이유 중 '먹을 시간이 없 어서'(28.1\%), ‘입맛이 없어서' $(26.6 \%)$ 및 '먹고 싶지 않 
아서' $(23.4 \%)$ 등은 다른 연구들에서도 나타나는 이유들이 나 '먹을 것이 없어서'가 $18.8 \%$ 로 나타나 아침 결식의 원인 중 하나가 식량부족이라는 것이 다른 연구에서와의 큰 차이 임을 알 수 있었다.

인도네시아의 경우 아침 결식과 함께 아침식사를 하는 경 우에도 식사의 질에서 차이가 있음을 지적하고 있다. 여러 연 구에서 항상 아침식사를 하는 경우에도 비정상적이고 낮은 품질의 아침식사를 하는 비율이 16.9 59\%의 범위를 보여 격차가 많음을 보여주고 있다 $[1,27]$. 아침식사로 음료 하 나 혹은 쿠키 한 조각만을 섭취하는 경우와 오전 10시 이후 의 늦은 아침식사가 대표적인 잘못된 아침식사로 지적되었 다 [13]. 또한 아침식사 권장 사항으로 과일을 많이 섭취하 고 [37], 유제품을 식사에 포함시키며, 고기류와 채소류의 반 찬과 함께 곡류를 섭취하거나 영양이 강화된 곡물 시리얼을 섭취할 것을 강조하였다 $[38,39]$. 이와 같은 맥락에서 인도 네시아 아동을 대상으로 한 연구를 종합한 보고 [40]에서도 인도네시아 아동들에게는 아침식사 권장만으로는 충분하지 않으며, 영양 균형적 아침식사로 개선하는 것이 함께 이루어 져야 할 시급한 문제임을 지적했다. 인도네시아 보건 장관 규 정 영양균형지침 [41]에서도 6세 19세 청소년에게 다양한 식품군을 섭취하고, 달고 짜고 기름진 음식을 제한하며, 아 침식사를 일상화 하는 등의 내용을 권장하고 있다. 특히 아 침식사 일상화 세부사항으로 인도네시아 영양권장량의 $15 \sim 30 \%$ 를 충족하는 식사를 할 것과 아침식사는 균형 잡힌 영양실현에 중요한 행동임을 명시하고 있으며, 매년 2월 실 시되는 국립 아침식사 주간(Pekan Sarspan nasional)에 전국의 주 또는 학교 등에서 아침식사를 장려하기 위한 행사 에 적극 참여할 것을 권장하고 있다 [41].

본 연구에서도 조사대상자의 약 $80 \%$ 가 아침으로 먹는 식 품의 종류가 매우 제한적임을 알 수 있었다. 특히 탄수화물 (25.6\%), 생선과 육류 (2.6\%), 채소 (18.6\%), 과일 (1.3\%) 및 음료 $(1.3 \%)$ 등 한 가지만 섭취하는 비율이 매우 높았다. 탄수화물군, 육류 및 생선, 채소 및 과일군 등 비교적 균형적 인 식사를 한 경우는 $10 \%$ 정도에 불과하였다. 6 12세를 대 상으로 한 아침식사에 대한 선행연구에서도 아침으로 주로 탄수화물과 반찬, 그리고 음료를 함께 섭취하는 경우가 $34.4 \%$ 로 가장 많았고, 탄수화물과 음료만 섭취하는 비율도 $23.7 \%$ 로 나타났다고 하였으며 [27], 일주일에 4회 이상 육류와 유 제품을 섭취하는 비율이 농촌지역과 도시지역이 각각 $0 \%$ 와 $18.5 \%$ 로 나타나 도시 아동에 비해 농촌지역의 아동들이 제 한적인 식품을 섭취하는 식생활을 보였다는 연구 결과 [24] 도 있었으며 이는 지역 간의 차이를 보여주는 자료이다. 또 한 본 연구결과에서 아침 식사 시 음료를 함께 섭취하는 비
율이 $31.4 \%$ 로 나타난 것과 관련하여 음료의 종류는 확인할 수 없었지만 단 음료를 섭취하는 인도네시아의 식습관을 고 려할 때 우려가 되는 부분이다. 인도네시아에서 실시된 선행 연구에서 미취학 아동 (3 5세)의 $29.3 \%$ 가 우유에 설탕이 $44 \%$ 함유된 음료를 정기적으로 섭취하며, 12 세의 $59.1 \%$ 가 설탕이 함유된 식품과 음료를 하루에 5 회 이상 섭취한다 [42]는 결과를 감안해 볼 때 추후 식사 시 단 음료를 함께 섭 취 하는 것에 대한 연구가 필요할 것으로 생각된다.

개발도상국의 영양문제는 영양부족에 의한 저체중의 문 제와 함께 고혈압, 당뇨병, 비만 등의 영양과잉의 문제가 공 존함으로써 영양불량의 이중부담(double burden of malnutrition, DBM)이 지적되고 있다[43]. 아동에 있어서 도 저체중 문제와 더불어 과체중과 비만의 문제가 공존하게 되면서 적절한 영양공급과 함께 영양교육을 통한 올바른 식 습관을 확립시키는 것이 매우 중요하다는 인식이 확산되고 있다. 2017년 4월부터 2018년 4월까지 인도네시아의 Bandung, Bogor, Tangerang 등 3개의 시에서 초등학교 교사 (221명), 학생 (4,713명), 그리고 학부모 (270명)의 건 강한 아침식사 인식에 관한 연구가 진행되었다. 교사와 학부 모를 대상으로 아침식사의 의의와 이점, 학생들의 아침식사 문제점, 안전하지 않은 간식, 아침식사 문제를 극복하기 위 한 노력 등의 내용을 포함한 영양교육을 진행하였다. 학생들 의 경우 건강한 아침식사를 아침마다 제공하면서. 균형 잡힌 영양과 건강한 아침식사에 대하여 친숙하고 잘 기억할 수 있 도록 만화와 노래를 통한 영양교육을 진행하였다. 영양교육 을 받은 교사와 학부모 모두 영양교육에 긍정적으로 참여 후 앞으로도 교육이 계속되길 희망하였고, 초등학생은 만화를 통한 교육이 흥미롭고 이해하기 쉽다고 응답하였다[1].

본 연구에서는 건강신념모델의 자기효능감과 인지된 민감 성이 아침식사하기 행동의도에 가장 큰 영향을 미쳤고, 인지 된 장애는 영향을 미치지 않았다. 반면 우리나라의 초등학생 의 식습관을 연구한 Lee[16]의 연구에서는 자기 효능감이 식습관에 가장 높은 영향요인인 것으로 나타났고, 인지된 이 득이 영향을 미치지 않는 것으로 확인되어 다소 상반되는 결 과를 보였다. 또한 건강신념모델을 이용한 선행연구에서 건 강에 좋지 않는 간식의 섭취를 줄이기 위한 영양교육 결과, 실험군에서 인지된 심각성과 인지된 이득이 교육 전 높은 점 수를 보였으며 영양교육 이후에도 각각 4.64점, 3.73점 상 승하여 대조군과 큰 차이를 보였다 [18]. 영양교육은 단지 지 식을 전달하는 수준에서 그치는 것이 아니라 실제로 아동의 실생활에 적용하여 잘못된 식습관이 올바르게 변화 되어질 때 그 의미를 갖는다 [2]. 따라서 본 연구결과를 조사대상 아 동들에게 적용한다면 아동들에게 아침결식을 했을 때 생길 
수 있는 건강의 문제에 민감하게 반응할 수 있도록 적절한 지 식 제공과 아동들 스스로 아침식사를 잘 할 수 있다는 자신 감을 심어주는 영양교육을 시행하는 것이 효과적일 것으로 생각된다. 또한 어머니가 아동들에게는 가장 영향력이 높음 을 감안하여 어머니들을 대상으로 아침식사의 중요성과 실 천에 필요한 실용적인 영양교육을 실시하는 것도 매우 필요 할 것으로 생각된다.

\section{요약 및 결론}

본 연구는 인도네시아 동부 Java의 초등학생을 대상으로 신체계측과 혈액검사 및 설문조사 등을 통하여 대상자들의 아침식사 실태를 조사하고, 아침식사하기 행동에 영향을 미 치는 요인을 파악하고자 실시하였다. 연구모형은 확대된 건 강신념모델의 다섯 가지 요인 (인지된 민감성, 인지된 심각 성, 인지된 이득, 인지된 장애, 자기 효능감)과 계획적 행동 이론의 주관적 규범 요인을 추가하여 아동들의 아침식사하 기 행동의도에 미치는 영향을 확인하였다. 그 결과는 다음과 같다.

1. 조사대상자들은 빈혈율 $21.2 \%, \mathrm{HAZ}$ 에 의한 발육부진 비율 $11.5 \%$ 로 영양결핍현상을 보였으며, BMIZ에 의한 중 등도 허약 $(14.7 \%)$ 과 과체중과 비만 $(12.2 \%)$ 이 공존함을 보여주었다.

2. 아침식사실태 결과, 등교 전 아침식사를 하지 않는 비율 이 $21.8 \%$ 였고, 아침결식의 이유 중 먹을 음식이 부족한 경 우 $(18.8 \%)$ 도 많은 비율을 차지하였다. 아침식사를 하는 경 우에도 질적으로 균형있는 식사를 하는 비율은 $10 \%$ 정도에 불과하였다.

3. 아침식사하기 행동의도를 묻는 질문에서 '아침식사를 할 때 영양을 생각해 골고루 섭취할 것이다'는 항목의 점수 가 가장 높았다.

4. 건강신념모델의 요인들 중 인지된 민감성, 인지된 심각 성, 인지된 이득 및 자기 효능감이 아침식사하기 행동의도와 상관성이 있음을 나타내었고. 이 중 자기 효능감 $(\beta=0.447$, $\left.\mathrm{R}^{2}=0.200\right)$ 과 인지된 민감성 $\left(\beta=0.373, \mathrm{R}^{2}=0.139\right)$ 이 아 침식사하기 행동의도에 가장 큰 영향을 미치는 것으로 나타 났다.

5. 아동들에게는 준거인 중 어머니의 주관적 규범이 가장 컸고, 주관적 규범과 아침식사 행동의도와도 양적인 상관이 있었으나 아침식사하기 행동의도에 미치는 영향에 관한 설 명력은 매우 낮았다.

이와 같은 연구 결과에 따라 인도네시아 조사 대상 아동들 의 아침식사하기 행동의도를 높이기 위해서는 아침식사를 하
지 않았을 때 질병에 걸릴 가능성이 높음을 충분히 인지시키 는 교육과 아동 스스로 아침식사를 잘 할 수 있을 것이라는 자신감과 기대를 높여주는 교육에 초점을 맞추는 것이 효과 적임을 확인할 수 있었다. 또한 아동들에게 실시하는 직접적 영양교육 뿐 아니라 가장 영향력이 있는 준거인인 어머니들 을 통한 간접적인 개입이 될 수 있는 방안을 모색하는 것이 필요할 것으로 생각된다.

\section{ORCID}

Ran Yi Kang: https://orcid.org/0000-0003-1223-427X

Soo Jin Lee: https://orcid.org/0000-0003-2418-9701

Ho Kyung Ryu: https://orcid.org/0000-0002-4212-7363

\section{References}

1. Stefani M, Harfika A, Anwar K, Humayah W, Pujilestari S, Azni IN et al. An integrated healthy breakfast education for teachers, school children, and parents in West Java. ICCD 2018; 1(1): 165-170.

2. Hong JK. A study on the professional guidance and counseling for children in elementary schools. J Elementary Educ 2002; 15(1): 1-20.

3. Susanto F. Breakfast skipper and breakfast eater: which is better. Int J Nutr Food Sci 2015; 4(5): 565-573.

4. Brown JL, Beardslee WH, Prothrow-Stith D. Impact of school breakfast on children's health and learning: An analysis of the scientific research [Internet]. Sodexo Foundation; 2008 [cited 2019 Jul 1]. Available from: http://us.stop-hunger.org/files/live/ sites/stophunger-us/files/HungerPdf/Impact\%20of\%20School \%20Breakfast\%20Study_tcm150-212606.pdf.

5. Huang CJ, Hu HT, Fan YC, Liao YM, Tsai PS. Association of breakfast skipping with obesity and health-related quality of life: evidence from a national survey in Taiwan. Int J Obes 2010; 34(4): 720-725.

6. The national institute of health research and development, Ministry of health, Republic of Indonesia. Report on result of national basic health research (RISKESDAS) [Internet]. Jakarta, Indonesia: Ministry of health, Republic of Indonesia 2007 [cited 2019 Jul 1]. Available from: http://biofarmaka.ipb.ac.id/biofarmaka/ 2014/Riskesdas2007\%20-\%20Report\%20on\%20Result\%20of\% 20National\%20Basic\%20Health\%20Research.pdf.

7. Trihono, MSc. Riset Kesehatan Dasar: Riskesdas 2013. Badan Penelitian dan Pengemb A Nagan Kesehatan Kementerian Kesehatan RI; 2013 [cited 2019 Jul 1]. Available from: http://www.depkes.go. $\mathrm{id} /$ resources/download/general/Hasil\%20Riskesdas\%202013.pdf.

8. Yang RJ, Wang EK, Hsieh YS, Chen MY. Irregular breakfast eating and health status among adolescents in Taiwan. BMC Public Health 2006; 6(1): 295.

9. Nurul Fadhilah A, Teo PS, Huybrechts I, Foo LH. Infrequent breakfast consumption is associated with higher body adiposity and abdominal obesity in Malaysian school aged children. PLoS 
One 2013; 8(3): e59297.

10. WHO Working Group. Use and interpretation of anthropometric indicators of nutritional status. Bull World Health Organ 1986; 64(6): 929-941.

11. Mei Z, Grummer-Strawn LM. Standard deviation of anthropometric Z-scores as a data quality assessment tool using the 2006 WHO growth standards: a cross country analysis. Bull World Health Organ 2007; 85(6): 441-448.

12. Kuczmarski RJ, Ogden CL, Guo SS, Grummer-Strawn LM, Flegal KM, Mei $Z$ et al. 2000 CDC growth charts for the United States: Methods and development [Internet]. National Center for Health Statistics, USA; 2002 [cited 2019 Jul 1]. Available from: https://stacks.cdc.gov/view/cdc/6451.

13. Hardinsyah $H$, Aries M. Jenis pangan sarapan dan perannya dalam asupan gizi harian anak usia 6-12 tahun di Indonesia. Jurnal Gizi dan Pangan 2012; 7(2): 89-96.

14. Sekiyama M, Roosita K, Othsuka R. Snack foods consumption contributes to poor nutrition of rural children in West Java, Indonesia. Asia Pac J Clin Nutr 2012; 21(4): 558-567.

15. Februhartanty J. Nutrition education: It has never been an easy case for Indonesia. Food Nutr Bull 2005; 26(2): S267-274.

16. Lee KA. Elementary school children's perceptions of traditional Korean foods, based on the health belief model. Korean J Nutr 2013; 46(1): 86-97.

17. Shin KO, Yoon JA, Je H, Hwang HJ, Lee Y, Choi JH. The effect of nutrition education based on health belief model for male college students in Seoul. Korean J Hum Ecol 2018; 27(4): 305-319.

18. Fathi A, Sharifirad G, Gharlipour Z, Hakimelahi J, Mohebi S. Effects of a nutrition education intervention designed based on the health belief model (HBM) on reducing the consumption of unhealthy snacks in the sixth grade primary school girls. Int $\mathrm{J}$ Pediatr 2017; 5(2): 4361-4370.

19. UNICEF. Child poverty and disparities in Indonesia: challenges for inclusive growth [Internet]. Jakarta UNICEF; 2013 [cited 2019 Jul 1]. Available from: https://www.unicef.org/indonesia/ Child_Poverty_Indonesia.pdf.

20. Lee CH. The effect of locus of control and health belief model on handwashing: expanding health belief model [master's thesis]. Hanyang University; 2015.

21. Kim JE. Study on predicting behavioral intention of breastfeeding among primigravida [Master's thesis]. Dongguk University; 2000.

22. Kim JE. Microbiological analysis of hands and education of handwashing among preschool children in a day care center [master's thesis]. Hanyang University; 2010.

23. WHO. Iron deficiency anaemia: assessment, prevention and control. A guide for programme managers [Internet]. Geneva: World Health Organization; 2001 [cited 2019 Jul 1]. Available from: http://www.who.int/nutrition/publications/micronutrients/anaemia iron_deficiency/WHO_NHD_01.3/en/index.html.

24. Insani PN, Rimbawan R, Palupi E. Dietary habits and nutritional status among school children in rural and urban area: a comparative study from Bogor, Indonesia. Future Food J Food Agric Soc 2018; 6(2): 55-66.

25. OECD/World Health Organization. Health at a glance: Asia/ Pacific 2012 [Internet]. OECD; 2013 [cited 2019 Jul 3].
Available from: https://apps.who.int/iris/bitstream/handle/10665/ 87269/9789264183902_kor.pdf?sequence $=3 \&$ isAllowed=y.

26. WHO. The world health report 2002: Reducing risks, promoting healthy life [Internet]. World Health Organization, Geneva; 2002 [cited 2019 Jul 1]. Available from: https://www.who.int/whr/2002/en/.

27. Hardinsyah MS. Sarapan sehat salah satu pilar gizi seimbang [Internet]. Ketua umum pergizi pangan; 2013 [cited 2019 Jul 1]. Available from: https://pergizi.org/images/stories/downloads/materi_ PESAN/materi3.pdf.

28. Rampersaud GC, Pereira MA, Girard BL, Adams J, Metzl JD. Breakfast habits, nutritional status, body weight, and academic performance in children and adolescents. J Am Diet Assoc 2005; 105(5): 743-760.

29. Evers S, Taylor J, Manske S, Midgett C. Eating and smoking behaviours of school children in southwestern Ontario and Charlottetown, PEI. Can J Public Health 2001; 92(6): 433-436.

30. Ming MF, Ying GC, Kassim M. Eating patterns of school children and adolescents in Kuala Lumpur. Malays J Nutr 2006; 12(1): 1-10.

31. So HK, Nelson EA, Li AM, Guldan GS, Yin J, Ng PC et al. Breakfast frequency inversely associated with BMI and body fatness in Hong Kong Chinese children aged 9-18 years. Br J Nutr 2011; 106(5): 742-751.

32. Barker M, Robinson S, Wilman C, Barker DJ. Behaviour, body composition and diet in adolescent girls. Appetite 2000; 35(2): 161-170.

33. Kosti RI, Panagiotakos DB, Zampelas A, Mihas C, Alevizos A, Leonard $\mathrm{C}$ et al. The association between consumption of breakfast cereals and BMI in schoolchildren aged 12-17 years: the VYRONAS study. Public Health Nutr 2008; 11(10): 10151021.

34. Kovarova M, Vignerova J, Blaha P, Osancova K. Bodily characteristics and lifestyle of Czech children aged 7.00 to 10.99 years, incidence of childhood obesity. Cent Eur J Public Health 2002; 10(4): 169-173.

35. Sjoberg A, Hallberg L, Hoglund D, Hulthen L. Meal pattern, food choice, nutrient intake and lifestyle factors in The Goteborg Adolescence Study. Eur J Clin Nutr 2003; 57(12): 1569-1578.

36. Keski-Rahkonen A, Kaprio J, Rissanen A, Virkkunen M, Rose RJ. Breakfast skipping and health-compromising behaviors in adolescents and adults. Eur J Clin Nutr 2003; 57(7): 842-853.

37. O'Neil CE, Nicklas TA. A review of the relationship between $100 \%$ fruit juice consumption and weight in children and adolescents. Am J Lifestyle Med 2008; 2(4): 315-354.

38. Cotton PA, Subar AF, Friday JE, Cook A. Dietary sources of nutrients among US adults, 1994 to 1996. J Am Diet Assoc 2004; 104(6): 921-930.

39. Whittaker P, Paul R. Tufaro PR, Rader JI. Iron and folate in fortified cereals. J Am Coll Nutr 2001; 20(3): 247-254.

40. Rampersaud GC. Benefits of breakfast for children and adolescents: Update and recommendations for practitioners. Am J Lifestyle Med 2008; 3(2): 86-103.

41. Menteri Kesehatan Republik Indonesia. Peraturan menteri kesehatan republik Indonesia nomor 41 tahun 2014 [Internet]. Jakarta, Indonesia; 2014 [cited 2019 Jul 1]. Available from: http:/ /hukor.depkes.go.id/uploads/produk_hukum/PMK\%20No.\%2041\% 
12 - 인도네시아 아동들의 아침식사 행동 영향 요인

20ttg\%20Pedoman\%20Gizi\%20Seimbang.pdf.

42. Imanningsih $\mathrm{N}$, Jahari $\mathrm{AB}$, Permaesih ID, Chan P, Amarra S. Consumption and sources of added sugar in Indonesia: a review. Asia Pac J Clin Nutr 2018; 27(1): 47-64.
43. Lee SJ, Ryu HK. Relationship between dietary intakes and the double burden of malnutrition in adults of Malang, Indonesia: An exploratory study. Nutr Res Pract 2018; 12(5): 426-435. 